\title{
A Cross-sectional Study to Test Mediation Model of Psychological Adjustment in Relationship Between Social Support and Mental Health
}

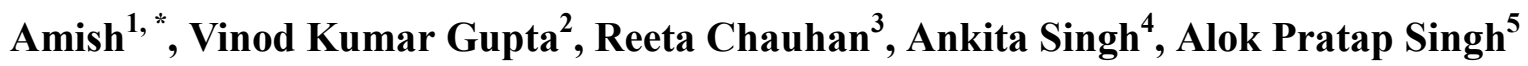 \\ ${ }^{1}$ Department of Psychology, Feroze Gandhi College, Rae Bareli (Associated with University of Lucknow), Lucknow, India \\ ${ }^{2}$ Department of Psychology, D. A. V. P. G. College, Gorakhpur, India \\ ${ }^{3}$ Department of Psychology, Women's College Samstipur, Bihar, India \\ ${ }^{4}$ Department of Clinical Psychology, Central Institute of Psychiatry (CIP), Ranchi, India \\ ${ }^{5}$ Department of Psychology, Allahabad University, Prayagraj, India
}

Email address:

amishbhu@gmail.com (Amish), vkgupta.psychology89@gmail.com (V. K. Gupta), msreetachauhan@gmail.com (R. Chauhan), ankitasinghcip@gmail.com (A. Singh), sriramalok@gmail.com (A. P. Singh)

${ }^{*}$ Corresponding author

To cite this article:

Amish Singh, Vinod Kumar Gupta, Reeta Chauhan, Ankita Singh, Alok Pratap Singh. A Cross-sectional Study to Test Mediation Model of Psychological Adjustment in Relationship Between Social Support and Mental Health. American Journal of Applied Psychology. Vol. 10, No. 5, 2021, pp. 101-109. doi: 10.11648/j.ajap.20211005.11

Received: September 4, 2021; Accepted: September 24, 2021; Published: September 29, 2021

\begin{abstract}
Since the outbreak of the Novel Corona virus Disease (COVID-19) many countries have resorted to lockdown to cope up with this situation including India. The lockdown has come at the cost of the economic health of Country and its cascading impact on all sections of the society. COVID-19 has not only caused depression and trauma in individuals, pressure of maintaining physical distance and confinement to their homes has caused uncertainty, anxiety and mental health problems. Amid the rising coronavirus pandemic problems surge across the country, many states of India have imposed restrictions and lockdown. This pandemic has affected the various aspects of human life and individuals are still facing post Covid-19 complications including stress, hopelessness, mental health problems and demotivating oneself. Lockdown and corona curfew have affected the normal life of human beings and it has been imposed to control the spreading of pandemic. This study is conducted to test the mediating role of psychological adjustment in social support-mental health relationship. Using a surveybased methodology and online questionnaires responses were obtained from 390 participants ( $N=390)$ of India. Cross-sectional correlational research design and snowball sampling method were used in this study. Obtained data was analyzed by using correlational, hierarchical regression analysis and mediation analysis by Hayes (PROCESS macro). Results of correlational analysis indicate that psychological adjustment and social support were found to be significantly positively correlated with mental health. Results of hierarchical regression analysis supports the obtained results of correlational analysis. Regression based approach; PROCESS macro was used to test the mediating role of psychological adjustment based on proposed mediation model. The results of mediation analysis revealed indirect effect of social support on mental health psychological adjustment. Psychological adjustment significantly partially mediated the social support-mental health relationship. The Findings from this study will provide empirical evidence for direct and indirect relationship among study variables. The results suggest that effective strategies primarily focusing on social support that are still needed to increase its effect on mental health through better psychological adjustment. The present study will be useful in policy making during such pandemics situations. Study limitations and future research were also discussed.
\end{abstract}

Keywords: Psychological Adjustment, Mental Health, Social Support, Hierarchical Multiple Regression Analysis, Mediation Model 


\section{Introduction}

Many nations in the world are fighting with coronavirus pandemic which have affected the human beings' health and also created the great deal of economic burden. Human networks are the major means of this COVID-19 pandemic disease transmission and, therefore, it is the biggest threat for humanity. In addition to physical impact, psychological impact of this pandemic also can be seen not only among victims or patients but also among general public, medical staff, older adults and children [6, 37, 21]. India is also a country that could not be untouched with this pandemic and it has its multifaceted effects on the general population of India who are experiencing undoubtedly different pressures and problems. Covid-19 pandemic is not only affecting the physical health but also affecting the mental health as well as different aspects of society [16]. In these situations of crisis and uncertainty of corona curfew and lockdown, maintaining psychological adjustments a major challenge to enhance the positive mental health of individuals in India.

World Health Organization defined the concept of mental health, which is a state of wellbeing in which the individual realizes his or her abilities, can cope with the normal stresses of life, can work productively and fruitfully and also can contribute to his or her community [34,35], can be promoted and determined by different biological, psychological, and social factors. Continuous researches on the variables to control the mental problems are still needed, especially in India with the sample of general population, it germane to study regarding the study variables and present study was an attempt to fill the gap. Findings will help to understand how the general population have been able to maintain their positive mental health as well as to identify the factors which mitigate harmful effects of stress and can enhance the social support and psychological adjustment of human beings.

\subsection{Relationship Between Social Support and Mental Health}

During Covid-19 pandemic situation, social support is one of the important factors which play important role in reducing various psychological and physiological problems. Social support can be an important predictor of mental health [12] as it has been found related with lesser mental health problems $[17,4,19,36]$. In another study, it has been found that social support play the buffering role against the negative influence of low resilience on mental health [20]. Social support is the provision of both psychological and tangible resources to satisfy an individual's need for concern, approval, belonging, and security [7]. A study has been conducted in China during Covid-19 pandemic situations and they found higher occurrence of mental health problems among adolescents who have low and medium levels of social support [24]. Self-determination theory gives further support to the premise that social interaction among individuals support to experience better well-being [27]. In other study, relationship between social support and psychological distress was found stronger than relationship between social support conditions of poverty [5]. Calvete and Connor-Smith have studied and fount that friends and family support decrease the effect of different psychological problems of students [3]. In another study conducted by researchers, found that during epidemics, individuals having high social support decreases the psychological pressure [1]. Here finally, we can think that social support is necessary for all human beings during pandemic and other problematic situations and certainly, it can reduces the mental health problems.

Hypothesis 1: Social support would be positively related with mental health.

\subsection{Psychological Adjustment and Mental Health}

In dark cloud of Covid-19 pandemic, psychological adjustment is necessary to minimize the repercussion of psychological problems. It can be operationalized in many studies either negatively (e.g., mental health problems) or positively (e.g., well-being). Life-satisfaction and self-esteem are the two significant factors of positive psychological adjustment [28, 33] while acculturative stress [29], somatic problems [e.g. sleeplessness and headaches; [14], or psychiatric symptoms [e.g. anxiety, depression, and suicidal ideation; [32] are used as indicators of the negative psychological adjustment. Psychological adjustment constructs defined as an individual's subjective sense of distress and ability to function in daily routine life, are typically transtheoretical and constructed to capture symptoms, wellbeing, and functioning within a single instrument [18]. There are numerous available studies to see the relationship between social support and psychological adjustment, to our best of knowledge, there is dearth of study to see the relationship of psychological adjustment and mental health during current pandemic situations. Here finally, we can expect that psychological adjustment can positively influence the mental health of individuals.

Hypothesis 2: Psychological adjustment would be positively related with mental health.

\subsection{Psychological Adjustment as a Mediator Variable in the Relationship Between Social Support and Mental Health}

Another very significant third objective is to study the role of psychological adjustment as a mediator variable in the relationship between social support and mental health. Theoretical foundation of the current study is built on the following contention. Here, presented models are tested based on assumption that individuals who receive social support, they obtain available psychological resources to lessen the perceived stress and maintain their psychological adjustment and this can also lead to better mental health. The availability of psychological resources minimizes the perceived stress and promote the positivity among individuals and improve the individuals' outcomes such as better psychological adjustment and mental health and lessen psychological problems. Thus, we can expect here that 
psychological adjustment would significantly mediate the relationship between social support and mental health. In this study, mediation model has tested in which psychological adjustment is used as a mediating variable in social supportmental health relationship. Social support provides the psychological resources which is necessary to enhance psychological adjustment, which in turn will enhance the mental health of individuals. Available psychological resources and better psychological adjustment can play significant roles in enhancing the mental health. Hence, we can think that psychological adjustment would significantly mediate the social support-mental health relationship.

Psychological adjustment was used as a mediator in relationship between different variables in numerous studies $[22,26]$. But there is dearth of studies in which psychological adjustment has been used a mediator in relationship between social support and mental health. This study will fill the research gap and will explore the new directions and opportunities for researchers.

Hypothesis 3: Psychological adjustment would be significantly mediated in the relationship between social support and mental health.

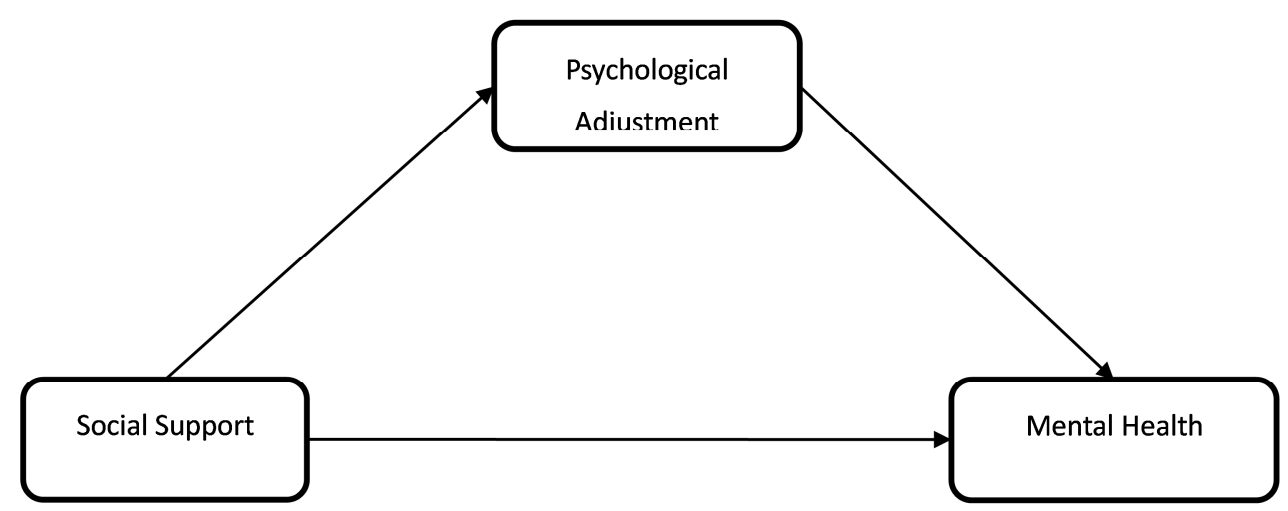

Figure 1. Conceptual Framework.

\section{Materials and Methods}

\subsection{Design}

For the present study, which is exploratory research in nature, a cross-sectional correlational research design was used to examine the relationship among the above variables to be studied. Self-reported questionnaires were used as a locus of measurement for collecting data.

\subsection{Participants}

The present study was conducted on 390 participants living in different states of India using snowball technique (a non-probability sample technique). The online survey was first disseminated to friends, students, family members, relatives, colleagues, teachers, researchers, and they were encouraged to pass it on to others via E-mail, Social media like Facebook, Messenger, and WhatsApp. Participants were not given any momentary rewards for completing the questionnaire.

\subsection{Measures}

\subsubsection{General Health Questionnaire (GHQ-12)}

The general health questionnaire-12 developed by Goldberg [11] was used in this research to measure mental health. It is widely used as a unidimensional instrument measuring psychological health (mental health) [10]. It consists of 12 items about health and welfare issues. The assessment was made using a four-point Likert scale from 4 to 1 . It is necessary to consider that high scores indicate a good level of mental health. Reliability of this scale was rechecked on the present sample and overall Cronbach's Alpha of this scale was found to be 0.81 .

\subsubsection{The Oslo 3-items Social Support Scale (OSS-3)}

To assess social support OSS-3 developed by Dalgard [9] was used. It consists of three items assessing the level of social support which provides a brief measure of social functioning and it is one of the best predictors of mental health. For the OSSS-3, the internal consistency could be regarded as acceptable with $\alpha=.640$. It has been recommended for epidemiological and population-based surveys. Reliability of this scale was rechecked on the present sample and Overall Cronbach's Alpha of this scale was found to be .61 . The relatively low value was probably due to this scale's brevity.

\subsubsection{Brief Adjustment Scale-6 (BASE-6).}

The BASE-6 is a brief self-report measure of general psychological adjustment developed for stand-alone use and as part of a measurement feedback system for ROM [31]. The item pool contains six items and assesses individuals' perceptions of emotional distress (three items: depression, anxiety and, anger) and related interference (three items: selfesteem, personal relationships, and occupational functioning). All six items were on a seven-point Likert scale $(1=$ not at all, $4=$ somewhat, $7=$ extremely $)$, initially higher scores indicating lower general psychological adjustment. It was changed during analysis and after that higher scores indicate good psychological adjustment. Reliability of this scale was rechecked on the present sample and overall Cronbach's Alpha of this scale was found to be 0.88 . 


\subsection{Common Method Variance Issue}

Common Method Variance (CMV) is potential threat to the validity of the relationship between variables because it is one of the main sources of measurement error [23]. It occurs when responses get affected by the other factors (i.e., social desirability bias, and halo effect) instead of the original predispositions of the respondents that the scale attempts to uncover. Common-method and single-source biases are common in one-time survey studies [23]. Thus, Harman's single-factor test was conducted to determine whether the dataset suffers from CMB issue or not. For this we run exploratory factor analysis by taking all the observed variables into the model and then in the extraction we constrain the number of factors to be 1 . So, in this dataset we found the maximum variance explained by a single factor of the constrained model is 26.456 percent which is quite satisfactory. It should be less than $50 \%$. We conclude that this dataset doesn't violate the issue of common method variance (CMV) because the variance explained by the single factor is less than $50 \%$.

\subsection{Procedure and Data Analyses}

During this COVID-19 pandemic situations, information was collected through E-mail, WhatsApp, Facebook, and Messenger. Before proceeding to the questionnaires, participants were asked to indicate that they were over 18 years of age; that his or her participation was voluntary; and that informed consent was being given. All participants (respondents) provided informed consent. In this study, descriptive statistics and Pearson correlation coefficients were done for data analysis. Hierarchical regression analysis was also done to see the association between social support and mental health, and between psychological adjustment and mental health. Statistical significance of the mediation effects was examined through the software developed by Hayes (2013), a regression-based approach: an approach based on the ordinary least squares regression model, and the bootstrap method with 5000 samples.

\section{Results}

Table 1. Summary of Demographic Characteristics of the Sample $(N=390)$.

\begin{tabular}{|c|c|c|}
\hline S. N. & Demographic Variables & Number and Percentage \\
\hline \multirow{9}{*}{1} & Age (in Years) & \\
\hline & $20-25$ & $137(35.1 \%)$ \\
\hline & $26-30$ & $105(26.9 \%)$ \\
\hline & $31-35$ & $91(23.3 \%)$ \\
\hline & $36-40$ & $24(6.2 \%)$ \\
\hline & $41-45$ & $20(5.1 \%)$ \\
\hline & $46-50$ & $4(1 \%)$ \\
\hline & $51-55$ & $5(1.3 \%)$ \\
\hline & Above 56 & $4(1 \%)$ \\
\hline \multirow{3}{*}{2} & Gender & \\
\hline & Male & $210(53.8 \%)$ \\
\hline & Female & $180(46.2 \%)$ \\
\hline \multirow{6}{*}{3} & Education & \\
\hline & Ph. D & $101(25.9 \%)$ \\
\hline & Postgraduate & $188(48.2 \%)$ \\
\hline & Undergraduate & $95(24.4 \%)$ \\
\hline & Intermediate & $4(1 \%)$ \\
\hline & High School & $2(.5 \%)$ \\
\hline \multirow{3}{*}{4} & Marital Status & \\
\hline & Married & $149(38.2 \%)$ \\
\hline & Unmarried & $241(61.8 \%)$ \\
\hline \multirow{4}{*}{5} & Homeplace & \\
\hline & Urban & $247(63.3 \%)$ \\
\hline & Semi Urban & $70(17.9 \%)$ \\
\hline & Rural & $73(18.7 \%)$ \\
\hline \multirow{4}{*}{6} & Living With & \\
\hline & Family & $323(82.8 \%)$ \\
\hline & Friends & $21(5.4 \%)$ \\
\hline & Alone & $46(11.8 \%)$ \\
\hline
\end{tabular}

Descriptive statistics, correlational analysis, regression analysis (hierarchical) and mediation analysis (Hayes' PROCESS macro) for testing the proposed hypotheses of the present study were performed by using SPSS and obtained results are reported in the tables. The demographic characteristics of 390 participants are also displayed in table 1. Descriptive statistics and inter-correlation for the variables are reported in table 2 .

Table 2. Mean, SD and Inter-Correlations of the variables used in this study.

\begin{tabular}{lllll}
\hline Variables & Mean & SD & 1 & 2 \\
\hline 1. Psychological Adjustment & 27.15 & 7.665 & 1 & $.114^{*}$ \\
2. Social Support & 9.32 & 2.404 & $.114^{*}$ & $.610^{* * *}$ \\
3. Mental Health & 38.19 & 5.68 & $.610^{* * *}$ & $.193 * * *$ \\
\hline
\end{tabular}

$* \mathrm{p}<.01, * * * \mathrm{p}<.001$

To examine the relationship of psychological adjustment and social support with mental health, correlational analysis was done. Results of Pearson's coefficient of correlation for the study variables are presented in the table 2 .

Results reported in the above-mentioned table 2 reveal that psychological adjustment was found to be significantly positively correlated (highly) with mental health $(r=.610$, $\mathrm{p}<.001$ ) and social support was also found to be significantly positively correlated with mental health $(r=.193, p<.001)$.
Further, hierarchical regression analysis was performed to find out the causal relationship and association of social support with mental health, and also psychological adjustment with mental health.

Note- Standardized Beta $(\beta)$ is reported in table 3

In this analysis age, gender, education, marital status, home place, and number of family members were entered in the first step and used as controlled variables. Psychological adjustment and social support were entered in the step 2 and 
step 3 of the model respectively and mental health (criterion variable) was entered in the dependent variable column of the SPSS.

Table 3. Summary of Results of regression analysis (hierarchical) for social support \& psychological adjustment as predictor variables and mental health as criterion variable.

\begin{tabular}{llll}
\hline & \multicolumn{3}{l}{ Mental Health } \\
\cline { 2 - 4 } & Step 1 & Step 2 & Step 3 \\
\hline Control Variables (First Step) & & & \\
Age & .120 & -.009 & -.021 \\
Gender & -.075 & -.024 & -.034 \\
Education & -.089 & -.031 & -.059 \\
Marital Status & .001 & -.008 & .012 \\
Home Place & -.037 & .010 & .004 \\
No. of Family Members & .026 & -.004 &.-008 \\
Predictor Variables (Second Step) & & & \\
Psychological Adjustment & & $.610 * * *$ & $.591 * * *$ \\
Third Step. Social Support & & $.142 * * *$ & \\
R & .160 & .612 & .627 \\
$\mathrm{R}^{2}$ & .026 & .375 & .393 \\
$\mathrm{R}^{2}$ change & .026 & .349 & .018 \\
F-change & 1.678 & $213.17 * * *$ & $11.78 * * *$ \\
$\mathrm{~F}^{\mathrm{a}}$ & 1.678 & $32.69 * * *$ & $30.88 * * *$ \\
\hline
\end{tabular}

a- Step 1 degree of freedom=6, 283; Step 2 degree of freedom =7, 282; Step 3 degree of freedom $=8,281$; Step 4 degree of freed ${ }^{*} \mathrm{p}<.05, * * \mathrm{p}<.01$, $* * * \mathrm{p}<.001$

Result of regression analysis (hierarchical) reveals that psychological adjustment was found significant predictor of mental health and also significantly positively associated with mental health $(\beta=.610, \mathrm{p}<0.001)$. However, social support was also found significant predictor of mental health and also found significantly positively associated with mental health $(\beta=.142, \mathrm{p}<0.001)$. Results of hierarchical regression analysis also reveals that different demographic variables used in this study were explaining $2.6 \%$ of total variance in mental health. Psychological adjustment was explaining $34.9 \%$ of total variance in mental health whereas social support was explaining $1.8 \%$ of the total variance in mental health.

Mediation analyses were done, and we tested the hypothesized model using PROCESS macro v3.3 by Andrew Hayes [13] with 5000 bootstrap samples. Total effect, direct, and indirect effects were reported in the table. Assumptions of mediation analysis were tested, and it was done with the recommendation by Hayes [13]. Simple mediation analysis was done by using 5000 bootstraps with Model number four at $95 \%$ confidence interval (CI). In Hayes' mediation analysis, bootstrapping method is used to generate an empirically derived representation of the sampling dispersal of the indirect effect [13] and these indirect effects found in the PROCESS output Indirect effects obtained from this analysis were considered significant at $\mathrm{p}<0.05$ when the $95 \%$ confidence interval for the indirect effect did not comprise zero.

To determine the simple mediation of psychological adjustment in social support-mental health relationship, PROCESS macro with bootstrapping method as recommended by Hayes [13] was used. In this method, nonstandardized beta coefficients are also calculated to reduce Type 1 errors due to sampling distribution. Bootstrap method was applied to study the indirect effects of the social support on mental health via psychological adjustment.

Table 4. Model Summary for the Simple Mediator Model Depicted in Figure 1.

\begin{tabular}{|c|c|c|c|c|c|c|c|c|c|c|}
\hline \multicolumn{11}{|l|}{ Consequent } \\
\hline & \multicolumn{5}{|c|}{ M Psychological Adjustment } & \multicolumn{5}{|c|}{ Y Mental Health } \\
\hline Antecedent & & Coeff. & $\mathbf{S E}$ & $\mathbf{t}$ & $\mathbf{p}$ & & Coeff. & SE & $\mathbf{t}$ & $\mathbf{p}$ \\
\hline X social support & $\mathrm{a}$ & .36 & .16 & 2.25 & .05 & $\mathrm{c}^{\mathrm{i}}$ & .30 & .09 & 3.14 & .001 \\
\hline M P. Adjustment & & - & - & - & - & $\mathrm{b}$ & .44 & .03 & 14.89 & .001 \\
\hline \multirow[t]{3}{*}{ constant } & $i_{1}$ & 23.77 & 1.55 & 15.36 & .001 & $\mathrm{i}_{2}$ & 23.44 & 1.15 & 20.44 & .001 \\
\hline & \multirow{2}{*}{\multicolumn{5}{|c|}{$\begin{array}{l}\mathrm{R}^{2}=.01^{*} \\
\mathrm{~F}(1,388)=5.08, \mathrm{p}<.05\end{array}$}} & & \multicolumn{4}{|c|}{$\mathrm{R}^{2}=.39 * * *$} \\
\hline & & & & & & & $\mathrm{F}(2,38$ & 122.70 & & \\
\hline
\end{tabular}

Table 5. Direct Effect of Social Support on Mental Health.

\begin{tabular}{|c|c|c|c|c|c|c|}
\hline \multirow{2}{*}{ Effect } & \multirow{2}{*}{$\boldsymbol{\beta}$} & \multirow{2}{*}{ SE } & \multirow{2}{*}{$t$} & \multirow{2}{*}{$\mathbf{p}$} & \multicolumn{2}{|c|}{ 95\% bias-corrected bootstrap CI } \\
\hline & & & & & LLCI & ULCI \\
\hline .30 & .13 & .09 & 3.14 & .00 & .11 & .48 \\
\hline
\end{tabular}

$\mathrm{N}=$ 390. PROCESS Model 4, Bootstrap sample size $=5,000$; LL, lower limit; UL, upper limit; CI, confidence interval. *p $<0.05$, ***p $<0.001$ (two-tailed).

Model summary for the simple mediator model were displayed in table 4 as depicted in figure 1 and also table 5 showed direct effect of social support on mental health which included the effect, $\mathrm{p}$ value, and $95 \%$ bias-corrected bootstrap CI $\left(\mathrm{c}^{1}=0.30\right)$. From the table 5 it was clear that a $95 \%$ bias corrected bootstrap confidence interval is completely above zero (.11 to .48). In both consequents, the CI did not include zero, which were pointed to a statistically significant relationship. Hence, it can be determined from the survey responses that individuals who receive high social support, their mental health also become good and they perform better.

The bias corrected bootstrap CI has become the most widely recommended method for inference about the indirect effect in mediation analysis [13]. A 95\% bias corrected bootstrap CI for indirect effect is mentioned in table 6 in which psychological adjustment studied as a mediating variable in relationship between social support and mental health. 
Table 6. Indirect Effect (or Mediation Effect).

\begin{tabular}{|c|c|c|c|c|c|c|c|}
\hline & \multirow{2}{*}{ Effect } & \multirow{2}{*}{$\boldsymbol{\beta}$} & \multirow{2}{*}{ SE } & \multirow{2}{*}{ t } & \multirow{2}{*}{$\mathbf{p}$} & \multicolumn{2}{|c|}{ 95\% bias-corrected bootstrap CI } \\
\hline & & & & & & LLCI & ULCI \\
\hline Total Effect & .46 & .19 & .12 & 3.88 & .00 & .23 & .69 \\
\hline Direct Effect & .30 & .13 & .09 & 3.14 & .00 & .11 & .48 \\
\hline Indirect Effect & .16 & .07 & .07 & & & .02 & .31 \\
\hline
\end{tabular}

$\mathrm{N}=390$. PROCESS Model 4, Bootstrap sample size $=5000$; LL=Lower limit; UL=Upper Limit, CI= confidence interval $* * * \mathrm{p}<0.001$ (two-tailed).

In this study, simple mediation model, a mediator variable i.e. psychological adjustment $(\mathrm{M})$ influences the association between antecedent variable i.e. social support $(\mathrm{X})$ and the outcome variable i.e. mental health (Y). Mediation model by Hayes (PROCESS macro; model no. 4) for the social support - mental health relationship through psychological adjustment is shown in table 6. Model coefficients are showed on each path of the model depicted in table 6 . Regression coefficients $a$ and $b$ are positive, meaning those that are comparatively higher in psychological adjustment are predictable to be better in mental health. The indirect effect of $\mathrm{X}$ on $\mathrm{Y}$ through $\mathrm{M}$ is the product of these two coefficients $a$ and $b$ [13]. Accordingly, $a b$ (0.16 for mental health) represents the impact of social support on mental health through psychological adjustment.

Estimated regression coefficients and their standard errors, the $\mathrm{p}$ values, $\mathrm{R}^{2}$, and model summary information for the simple mediation model is showed in Table 4. Each of these two conditional process models representing psychological adjustment, and mental health are significant with $\mathrm{R}^{2}$ ranging from $0.01(\mathrm{p}<.050)$ to $0.39(\mathrm{p}<0.001)$. The regression coefficients for social support $(.30, \mathrm{p}<0.001)$ and psychological adjustment $(0.44, \mathrm{p}<.001)$ are significant on mental health consequent. A $95 \%$ bias-corrected bootstrap confidence interval is entirely above zero i.e., 0.02 to 0.31 for mental health. Therefore, the mediation effect of psychological adjustment on social support-mental health relationship is supported which is depicted in figure 2 .

In the figure 2, social support has a direct effect on psychological adjustment and psychological adjustment has direct effect on mental health. Figure 2 clearly displayed that psychological adjustment partially mediated the relationship between social support and mental health.

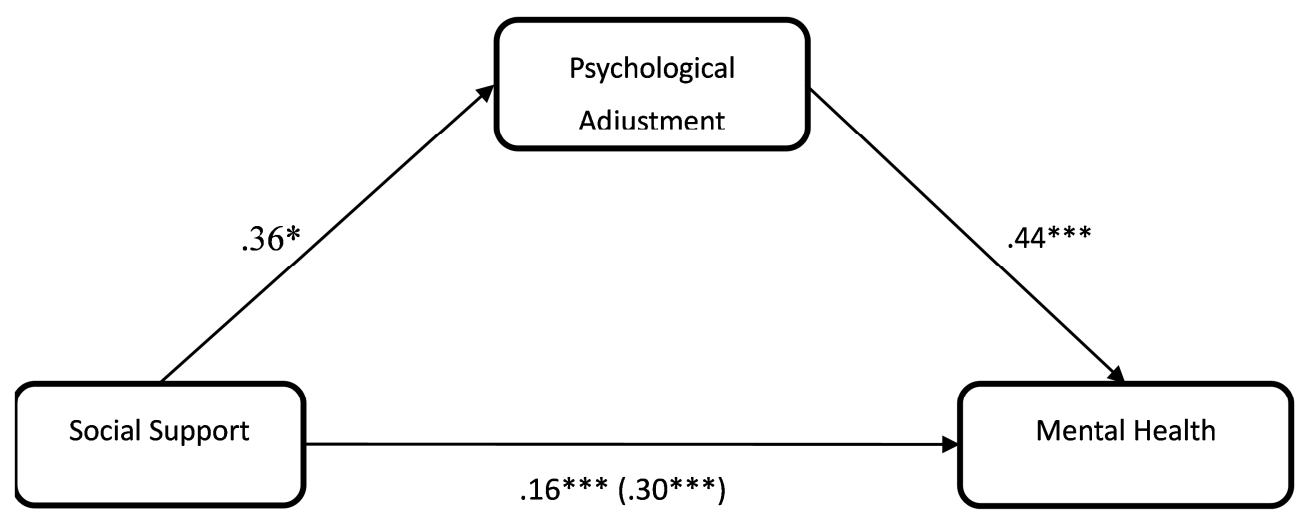

Figure 2. A statistical diagram of the mediator model (Direct and Indirect Effect).

\section{Discussion}

Present developing crises of Covid-19 have brought significant attention of psychologists, psychiatrists and mental health professionals to think on various psychosocial aspects to cope with fear, stress, anxiety and mental health problems during and after lockdown. The entire world is affected from this adversity. Covid-19 has not only caused depression and trauma in individuals but economic insecurity, pressure of maintaining physical distance and confinement to their homes has also caused mental health problems, uncertainty, and anxiety. Main objective of this study was to examine role of psychological adjustment as a mediator variable between social support and mental health and other objectives of the study was to study the role of psychological adjustment in the mental health and to study the role of social support in the mental health. Correlation analysis, hierarchical multiple regression analysis and also the mediation analysis by Hayes for testing the hypotheses was carried. Correlation analysis reveals that psychological adjustment and social support were found significantly positively correlated with mental health. Hierarchical regression analysis also conforms the results obtained from correlation analysis. Hierarchical multiple regression analysis also revealed that psychological adjustment and social support were found important and significant predictors of mental health. Both variables, social support and psychological adjustment were found significantly positively associated with individuals' mental health.

Thus, it was seen during this turbulent environment of coronavirus pandemic that individuals having more social 
support was found in less mental health problems conditions. During this coronavirus pandemic situations, maintaining psychological adjustment of individuals is big challenge. Psychological adjustment balances the needs of challenges faced by individuals' obstacles present in the environment and plays significant role in reducing the mental health problems. These findings are in accordance with expanding literature and support previous research done by various academicians \& researchers. For example, Berkman and Glass [2], Cohen, Gottlieb, and Underwood [8], Kawachi, and Berkman [15], and Qiong Ying, Shi Feng, and Ling [25] in their studies found the positive role of social support in health, emotional health and well-being while negatively associated with stressful events experiences and mental health problems. Hypothesis one and two are in accordance with the results obtained from correlation and hierarchical regression analysis and they are accepted.

A simple mediation model was also tested through mediation analysis by Hayes [13]. To study the role of psychological adjustment as a mediator variable in social support-mental health relationship, Process macro v3.3 was used. In this study social support was used as predictor variable and mental health as a criterion variable. For study the direct and indirect effect mediator analysis was done in which psychological adjustment has been studied as a mediator variable between predictor and criterion variable. Conceptual framework has been analyzed by using IBM SPSS, as well as Process Macro v3.3 running "simple mediation-model number 4" [13]. Specifically, it was proposed that psychological adjustment would be significantly mediated the relationship between social support and mental health. For this purpose, it was hypothesized that social support would have indirect effect with mental health through psychological adjustment and direct effect with mental health of individuals. Furthermore, after adding psychological adjustment in this model, the coefficient of social support was significantly reduced; this effect was needed to determine whether psychological adjustment sequentially partially mediated social supportmental health relationship. In the direct effect, significant association of social support and mental health was found and it was reduced when the effect of psychological adjustment was included in this model. Thus, social support enhance the mental health through psychological adjustment of individuals. Results showed that social support also has indirect effect with mental health through psychological adjustment. Result of the simple mediation analysis by PROCESS macro clearly indicates that psychological adjustment as a mediating variable partially mediated the social support-mental health relationship.

The findings of this study contribute that improving psychological adjustment among individuals is necessary because it has noteworthy indirect effect in enhancing the significant effect of the predictor variable (social support) on criterion variable (mental health). Regarding the simple mediation analysis, psychological adjustment partially mediated the social support-mental health relationship. In this pandemic situation, increasing social support and psychological adjustment can be important variables in enhancing the positivity and better mental health among individuals which will be very beneficial for all human beings. In mediation analysis by PROCESS macro, two path mediation model of this study showed 39\% variance (as mentioned in table 4) in mental health of individuals which is also found significant. Psychological adjustment not been studied simultaneously as mediator variables but have been studied independently as a mediator in different studies. Psychological adjustment has not been studied as a mediator variable in social support and mental health relationship but in some studies, it has been used a mediator between other variables. In one study, psychological adjustment was found significant mediating variable which mediated the relationship between acculturation and mental health 2019 [30]. Hypothesis three of the study was that psychological adjustment would be significantly mediated the social support-mental health relationship. Result of mediation analysis also partially support the hypothesis because psychological adjustment partially mediated the relationship between social support and mental health of individuals. Hence, this hypothesis three is partially accepted.

\section{Strengths, Limitations and Future Research}

This study has numerous strengths which should be addresses. This is an important empirical study in which psychological adjustment has been used a mediator variable in relationship between social support and mental health of the common individuals in current coronavirus pandemic situation. Also, to understand the mechanism to enhance their mental health conditions, simple mediation model has been used related to study variables. It also provides important insight for future studies.

Limitations of this study should be addressed and also it is not free from any limitations. Like any study, it also includes few shortcomings. First limitation of this study was that cross-sectional research design was used in this study which impedes to establish the cause and effect relationship. Therefore, to establish cause and effect relationship and to decrease such biases as well as for long-term outcomes, future research should apply multiple methods like longitudinal and experimental research methods to collect data and to increase the ameliorate of findings of this study. We have not manipulated any variables and also not used random sampling method. Reponses of the participants were obtained by using self-administered questionnaires, it is also another limitation which might be influenced by social desirability. Another limitation of the study was to use online survey. Size of the sample might be another limitation of the study as there only 390 individuals that have been taken in this study, so in future more representative sample should be included. Other limitation is that there might be other mediating variables which may play important role between 
social support and mental health which should be discussed.

Also, future studies should also be conducted by including other mediating variables in relationship between social support and mental health of individuals which should be discussed. Future research should also be conducted in other culture and context. Significantly, longitudinal and experimental research are needed to establish the causal relationship between study variables. Cross-cultural studies should be conducted in future. Future research should also include more representative sample.

\section{Conclusions and Implications}

Although many studies are needed before drawing any definitive conclusions, the present study suggests that psychological adjustment and social support predicted the mental health of individuals and also, they play significant role in decreasing mental health problems and enhancing positive mental health of individuals during lockdown and corona curfew due to coronavirus pandemic. Findings obtained in the current study also showed that psychological adjustment was significant mediating factor to explain the mechanism of how social support which will amplify the mental health of individuals. Psychological adjustment partially mediated social support-mental health relationship. Increasing psychological adjustment can play significant role in enhancing the mental health of individuals having enough social support during current Covid-19 pandemic situations.

Many implications of this should also be highlighted which will be beneficial for many individuals for boosting their positive mental health during current crisis and uncertain situation arising from Covid-19 pandemic. To date, there is still uncertainty about the peak of the present pandemic and there is no proper treatment available. Vaccinations are continuing by many countries. It is also true that this pandemic is not last as in future many epidemic, pandemic, and other natural disasters may take place and to face and manage those challenges our findings can be useful for making policy and developing intervention programs considering the important role of psychological adjustment and social support in enhancing mental health of general public so that they could develop resilience to cope the situation and manage their day to day life activities.

\section{Funding}

The authors did not receive any financial support and help for conducting this study, authorship and publication. The authors did not receive funding or benefit from neither industry nor elsewhere for this research.

\section{Conflict of Interest}

The authors declared no potential conflicts of interest with respect to the research, authorship, and/or publication of this study.

\section{Acknowledgements}

This study was conducted by collecting data from online resources (E-mail, WhatsApp, Facebook, and Messenger). All authors equally contributed to the data collection, entire process of writing and revision of this research and also, they approved the final version of this research. All the authors wish to thank all the participants and online resource provider platform to make the google form for collecting the data during this research.

\section{References}

[1] Bai, Y. X., Gegan, T., Hai, H., Liu, Z. H., Wang, W. R., Wang, Z. G., (2005). Correlation between psychological changes of the community crowd and the social support in grave public health event. Inner Mongolia Medical Journal. 37 (04): 295297. http://en.cnki.com.cn/ Articleen /CJFDTotalNMYZ200504003.htm.

[2] Berkman, L. F., \& Glass, T. (2000). Social integration, social networks, social support, and health. In L, F, Berkman, \& I, Kawachi (Eds), Social epidemiology (pp. 137-173). Oxford, UK: Oxford Press University.

[3] Calvete, H. \& Connor-Smith, J. K. (2006). Perceived social support, coping, and symptoms of distress in American and Spanish students. Anxiety, Stress, and Coping, 19 (1): 47-65.

[4] Cao, W., Fang, Z., Hou, G., Han, M., Xu, X., Dong, J., \& Zheng, J. (2020). The psychological impact of the COVID-19 epidemic on college students in China. Psychiatry Research, 287, 112934. https://doi.org/10.1016/j.psychres.2020.112934.

[5] Caron, J., Latimer, E., \& Tousignant, M. (2007). Predictors of psychological distress in low- income populations of Montreal. Canadian Journal of Public Health, 98 (Suppl 1): S 35- 44.

[6] Chen, Q., Liang, M., Li, Y., Guo, J., Fei, D., Wang, L.,... Zhang, Z. (2020). Mental health care for medical staff in China during the COVID-19 outbreak. The Lancet Psychiatry. 7 (4): e15-e16. http://doi:10.1016/S2215-0366(20) 30078-X.

[7] Cohen, S. (2004). Social relationships and health. American Psychologist, 59 (8), 676-684. https://doi.org/10.1037/0003066X.59.8.676.

[8] Cohen, S., Gottlieb, B. H., \& Underwood, L. G. (2001). Social relationships and health: Challenges for measurement and intervention. Advances in Mind-Body Medicine, 17 (2): 129141.

[9] Dalgard, O. S. (1996). Community health profile as a tool for psychiatric prevention. In D. R. Trent, C. Reeds \&Aldershot (Eds.). Promotion of Mental Health. United Kingdom: Ashgate Publishing.

[10] Gao, F., Luo, N., Thumboo, J., Fones, C., Li, S., \& Cheung, Y. B. (2004). Does the 12-item General Health Questionnaire contain multiple factors and do we need them? Health and Quality of Life Outcomes, 2, 63. https://doi.org/10.1186/14777525-2-63.

[11] Goldberg, D. (1972). The detection of psychiatric illness by questionnaire: A technique for the identification and assessment of non-psychotic psychiatric illness. London, New York: Oxford University Press. 
[12] Gu, Y., Hu, J., Hu, Y., \& Wang, J. (2016). Social supports and mental health: A cross-sectional study on the correlation of selfconsistency and congruence in China. BMC health services research, 16, 207. https://doi.org/10.1186/s12913-016-1463-x.

[13] Hayes, A. F. (2013). Introduction to mediation, moderation, and conditional process analysis: A regression-based approach. New York, NY: Guilford Press.

[14] Kaczmarek, P. G., Matlock, G., Merta, R., Ames, M. H., \& Ross, M. (1994). An assessment of international college student adjustment. International Journal for the Advancement of Counselling, 17 (4): 241-247. https://doi.org/10.1007/BF01407740.

[15] Kawachi, I., \&Berkman, L. F. (2001). Social Ties and Mental Health. Journal of Urban Health, 78 (3): 458-67. https://doi:10.1093/jurban/78.3.458.

[16] Khan, S., Siddique, R., Li, H., Ali, A., Shereen, M. A., Bashir, N., \&Xue, M. (2020). Impact of coronavirus outbreak on psychological health. Journal of Global Health, 10 (1), 010331. https://doi.org/10.7189/jogh.10.01033.

[17] Khoury, J. E., Atkinson, L., Bennett, T., Jack, S. M., \& Gonzalez, A. (2021). COVID-19 and mental health during pregnancy: The importance of cognitive appraisal and social support. Journal of Affective Disorders, 282, 1161-1169. https://doi.org/10.1016/j.jad.2021.01.027.

[18] Kraus, D. R., Seligman, D. A., \& Jordan, J. R. (2005). Validation of a behavioral health treatment outcome and assessment tool designed for naturalistic settings: The Treatment Outcome Package. Journal of Clinical Psychology, 61 (3): 285-314. https://doi.org/10.1002/ jclp.20084.

[19] Lebel, C., MacKinnon, A., Bagshawe, M., Tomfohr-Madsen, L., \& Giesbrecht, G. (2020). Elevated depression and anxiety symptoms among pregnant individuals during the COVID-19 pandemic. Journal of Affective Disorders, 277, 5-13. https://doi.org/10.1016/j.jad.2020.07.126.

[20] Li, F., Luo, S., Mu, W., Li, Y., Ye, L., Zheng, X., Xu, B., Ding, Y., Ling, P., Zhou, M., \& Chen, X. (2021). Effects of sources of social support and resilience on the mental health of different age groups during the COVID-19 pandemic. BMC psychiatry, 21 (1), 16. https://doi.org/10.1186/s12888-020-03012-1.

[21] Li, S. W., Wang, Y., Yang, Y. Y., Lei, X. M., \& Yang, Y. F., (2020). Analysis of influencing factors of anxiety and emotional disorders in children and adolescents during home isolation during the epidemic of novel coronavirus pneumonia. Chinese Journal of Child Health. 1-9.

[22] Li, Y., Yang, Y., Zhang, R., Yao, K., \& Liu Z. (2015). The mediating role of mental adjustment in the relationship between perceived stress and depressive symptoms in hematological cancer patients: A cross-sectional study. PLoS ONE, 10 (11), e0142913. https://doi.org/10.1 371/journal.pone.0142913.

[23] Podsakoff, P. M., MacKenzie, S. B., Lee, J. Y., \& Podsakoff, N. P. (2003). Common method biases in behavioural research: A critical review of the literature and recommended remedies. Journal of Applied Psychology, 88 (5): 879-903.

[24] Qi, M., Zhou, S. J., Guo, Z. C., Zhang, L. G., Min, H. J., Li, X. M., \& Chen, J. X. (2020). The effect of social support on mental health in Chinese adolescents during the outbreak of COVID-19. The Journal of Adolescent Health: Official Publication of The Society for Adolescent Medicine, $67 \quad$ (4), 514-518. https://doi.org/10.1016/j.jadohealth.2020.07.001.
[25] Qiong Ying, X., Shi Feng, L., \& Ling, Y. (2019). Perceived social support and mental health for college students in mainland China: The mediating effects of self-concept, Psychology, Health \& Medicine, 24 (5): 595-604, DOI: 10.1080/13548506.2018.1549744.

[26] Romera, E. M., Gómez-Ortiz, O., \& Ortega-Ruiz, R. (2016). The mediating role of psychological adjustment between peer victimization and social adjustment in adolescence. Frontiers $\begin{array}{llll}\text { in } & \text { psychology, } & \text { 7, }\end{array}$ https://doi.org/10.3389/fpsyg.2016.01749.

[27] Ryan R. M., \& Deci, E. L. (2000). Self-determination theory and the facilitation of intrinsic motivation, social development, and well-being. American Psychologist, 55 (1): 68-78. https://doi.org/10.1037/0003-066X.55.1.68.

[28] Sam, D. L. (2001). Satisfaction with life among international students: An exploratory study. Social Indicators Research, 53 (3): 315-337. https://doi. org/10.1023/A:10071086 14571.

[29] Sandhu, D. S., \&Asrabadi, B. R. (1994). Development of an acculturative stress scale for international students: Preliminary findings. Psychological Reports, 75 (1): 435-448. https://doi. org/10.2466/pr0.1994.75.1.435.

[30] Shi, L., Chen, W., Bouey, J. H., Lin, Y., \& Ling, L. (2019). Impact of acculturation and psychological adjustment on mental health among migrant adolescents in Guangzhou, China: A cross-sectional questionnaire study. BMJ Open, 9 (5): e022712. https://doi.org/10.1136/bmj open-2018-022712.

[31] Smith, L. R., Lee K. S., Ward, S. R., Chambers, H. G., \& Lieber, R. L. (2011). Hamstring contractures in children with spastic cerebralpalsy result from a stiffer extracellular matrix and increased in vivo sarcomere length. The Journal of Physiology, 589: 2625-39. https://doi.org/10.1113/jphysiol.2010.203364.

[32] Sümer, S., Poyrazli, S., \& Grahame, K. (2008). Predictors of depression and anxiety among international students. Journal of Counseling \& Development, $86 \quad$ (4): 429-437. https://doi.org/10.1002/j.1556-6678.2008. tb00531. x.

[33] Wei, M., Ku, T. Y., Russell, D. W., Mallinckrodt, B., \& Liao, K. Y. H. (2008). Moderating effects of three coping strategies and self-esteem on perceived discrimination and depressive symptoms: A minority stress model for Asian international students. Journal of Counseling Psychology, 55 (4): 451-462. https:// doi.org/10.1037/a0012511.

[34] World Health Organization. (2001). Mental Health: New Understanding, New Hope. The World Health Report. Geneva, Switzerland: World Health Organization.

[35] World Health Organization. (2003). Investing in mental health. Geneva: World Health Organization. https://apps.who.int/iris/handle/10665/42823.

[36] Xiao, H., Zhang, Y., Kong, D., Li, S., \& Yang, N. (2020). The Effects of Social Support on Sleep Quality of Medical Staff Treating Patients with Coronavirus Disease 2019 (COVID-19) in January and February 2020 in China. Medical Science Monitor: International Medical Journal of Experimental and Clinical Research, 26, 9923549. https://doi.org/10.12659/MSM.923549.

[37] Yang, Y., Li, W., Zhang, Q., Zhang, L., Cheung, T., \& Xiang, Y. T. (2020). Mental health services for older adults in China during the COVID-19 outbreak. The Lancet. Psychiatry. 7 (4): e19. http://doi:10.1016/S2215-0366(20)30079-1. 